\title{
Correction to: Magnetic dipole interaction with multipole magnetic field lines of neutron stars
}

\author{
H M Tedila ${ }^{1,2,3 *}$ (1) \\ ${ }^{1}$ Xinjiang Astronomical Observatory, Chinese Academy of Sciences, Urumqi 830011, China \\ ${ }^{2}$ University of Chinese Academy of Sciences, Beijing 100049, China \\ ${ }^{3}$ Arba Minch University, Arba Minch 21, Ethiopia
}

\section{Correction to: Indian J Phys}

https://doi.org/10.1007/s12648-021-02039-8

The article "Magnetic dipole interaction with multipole magnetic field lines of neutron stars", written by H M Tedila, was originally published online on the publisher's internet portal on 14 March 2021 with Open Access under a Creative Commons Attribution (CC BY) license 4.0.
With the author's decision to cancel Open Access the copyright of the article changed on 12 May 2021 to (c) Indian Association for the Cultivation of Science 2021 with all rights reserved.

The original article has been corrected.

Publisher's Note Springer Nature remains neutral with regard to jurisdictional claims in published maps and institutional affiliations.

The original article can be found online at https://doi.org/10.1007/s12648-021-02039-8.

*Corresponding author, E-mail: habta125@xao.ac.cn 